\title{
Nickel oxide Nano-Rods/Plates as a High Performance Electrode Materials for Supercapacitors; Electrosynthesis and Evolution of Charge Storage Ability
}

\author{
Mustafa Aghazadeh ${ }^{1}$, Amir Rashidi ${ }^{1}$, Mohammad Reza Ganjali ${ }^{2,3, *},{ }^{*}$ Mohammad Ghannadi Maragheh ${ }^{1}$ \\ ${ }^{1}$ NFCRS, Nuclear Science and Technology Research Institute (NSTRI), P.O. Box 14395-834, Tehran, \\ Iran \\ ${ }^{2}$ Center of Excellence in Electrochemistry, University of Tehran, Tehran, Iran \\ ${ }^{3}$ Biosensor Research Center, Endocrinology and Metabolism Molecular-Cellular Sciences Institute, \\ Tehran University of Medical Sciences, Tehran, Iran. \\ *E-mail: ganjali@khayam.ut.ac.ir
}

doi: $10.20964 / 2016.12 .115$

Received: 11 September 2016 / Accepted: 27 October 2016 / Published: 10 November 2016

The nano-rods/plates nickel oxide were prepared by pulse electrodeposition followed by calcination of nickel hydroxide. The formation mechanism of the nickel oxide through this route was explained. The prepared nickel oxide was characterized using XRD, SEM, IR and DSC-TG analyses. The supercapacitive behavior of the $\mathrm{NiO}$ nano-rods/plates was evaluated through cyclic voltammetry and charge-discharge measurements. The obtained data showed that the prepared oxide is able to deliver the $\mathrm{SC}$ values as high as $1445 \mathrm{~F} \mathrm{~g}^{-1}, 1307 \mathrm{~F} \mathrm{~g}^{-1}, 1147 \mathrm{~F} \mathrm{~g}^{-1}, 1006 \mathrm{~F} \mathrm{~g}^{-1}, 892 \mathrm{~F} \mathrm{~g}^{-1}$ and $772 \mathrm{~F} \mathrm{~g}^{-1}$ at the applied current load of 1, 2, 3, 5, 7 and $10 \mathrm{~A} \mathrm{~g}^{-1}$, respectively. The values approved the remarkable supercapacitive performance of the $\mathrm{NiO}$ nano-rods/plates. The fabricated electrode is also exhibits the capacity retentions of $91.8 \%$ and $75.9 \%$ after 3000 cycling at the current loads of 2 and $10 \mathrm{~A} \mathrm{~g} \mathrm{~g}^{-1} \mathrm{~A} / \mathrm{g}$, revealing. Based on the obtained results, it can be concluded that the fabricated oxide can be a proper material for high performance supercapacitors.

Keywords: Nickel oxide; Nanorods/plates; Pulse base generation; Heat treatment; Supercapacitors

\section{FULL TEXT}

(C) 2016 The Authors. Published by ESG (www.electrochemsci.org). This article is an open access article distributed under the terms and conditions of the Creative Commons Attribution license (http://creativecommons.org/licenses/by/4.0/). 